\title{
The efficiency and safety of trastuzumab and lapatinib added to neoadjuvant chemotherapy in Her2-positive breast cancer patients: a randomized meta-analysis
}

\author{
This article was published in the following Dove Press journal: \\ OncoTargets and Therapy \\ 30 May 2016 \\ Number of times this article has been viewed
}

\author{
Zhe-Ling Chen \\ Yan-Wei Shen \\ Shu-Ting Li \\ Chun-Li Li \\ Ling-Xiao Zhang \\ Jiao Yang \\ Meng Lv \\ Ya-Yun Lin \\ Xin Wang \\ Jin Yang
}

Department of Medical Oncology, The First Affiliated Hospital of Xi'an Jiaotong University, Xi'an, Shaanxi, People's Republic of China
Correspondence: Jin Yang Department of Medical Oncology, The First Affiliated Hospital of Xi'an Jiaotong University, No 277 Yanta West Road, Xi'an, Shaanxi 71006I, People's Republic of China

Tel +862985323422

Fax +862985323422

Email1473106133@qq.com
Background: The addition of human epidermal growth factor receptor 2 (Her2) therapies to neoadjuvant chemotherapy (NAC) during treatment of Her2-positive breast cancer has been proposed as an effective way to improve the prognosis. However, the treatment outcomes of adding trastuzumab, lapatinib, or both to NAC were not unequivocal in randomized clinical trials. Based on these data, a meta-analysis was performed.

Objective: The main objective was to evaluate the efficiency and safety of trastuzumab and lapatinib added to NAC for treatment of Her2-positive breast cancer.

Methods: ClinicalTrials.gov and PubMed were searched for randomized clinical trials that compared trastuzumab, lapatinib, or both, added to NAC. The main endpoint was a pathologically complete response (pCR) rate, in breast only or in breast and lymph nodes. The drug safety and the influence of hormone-receptor status, comparing the clinical response and the rate of breast conservation, were evaluated.

Results: A total of eight publications were included in the primary analysis, designed as two or three subgroups. The cumulative cases were 2,349 and the analyses of all the clinical trials showed that the pCR rate was significantly higher in the group receiving trastuzumab than that in the group with lapatinib, either in breast only $(P=0.001)$ or in breast and lymph nodes $(P=0.0001)$. Similar results could be seen in comparisons of the combination versus trastuzumab group. Further studies of subgroups divided into hormone receptor-positive or-negative patients showed that the addition of trastuzumab or dual Her2-targeted therapy significantly improved the pCR rate in patients who were hormone-insensitive. Regarding the toxic effects, we found more grade 3 and 4 toxic effects, such as diarrhea, skin disorder, and hepatic biochemical changes in the lapatinib and combination groups. No temporally significant differences were found when the clinical response and the rate of breast conservation in the groups were analyzed.

Conclusion: The combination of trastuzumab and lapatinib was superior to single-agent treatment for improved pCR rate. However, combination treatment was not effective in improving the rate of breast conservation. Furthermore, a higher risk for toxicity was associated with combined administration.

Keywords: breast cancer, trastuzumab, lapatinib, human epidermal growth factor receptor, neoadjuvant, pathologically complete response

\section{Introduction}

The overexpression of human epidermal growth factor receptor 2 (Her2) can be found in $15 \%-20 \%$ of breast cancer patients, which is associated with significantly shortened 
disease-free and overall survival. ${ }^{1}$ The expression product of the Her 2 gene is a membrane spanning oncogenic protein that is processed externally at the membrane. Because of its specific overexpression in tumor cells, Her2 can be used as a target antigen for breast cancer therapy.

The use of trastuzumab, a chimeric monoclonal antibody recognizing the extracellular region of the Her2 protein, has dramatically changed the outcome of patients with Her2-amplified breast cancer. ${ }^{2}$ Pegram et $\mathrm{al}^{3}$ reported that when given single-therapy trastuzumab as the first-line treatment in 112 Her2-positive breast cancer patients, the total responsive rate was $23 \%$. The responsive rate in a subgroup of patients that overexpressed Her-2 was 31\%. Trastuzumab has therefore been shown to be effective when used as a single agent, or when used with other chemotherapeutic drugs.

Recently, many other inhibitors such as small molecule tyrosine-kinase inhibitors, monoclonal antibodies, and antibody-drug conjugates are emerging as additional treatments. ${ }^{2}$ However, although these new drugs show promise, the most efficacious preoperative Her2 inhibitory agents are still being explored. Currently, the overexpression of the epidermal growth factor receptor and Her2 can be found in $20 \%-30 \%$ of the patients. Lapatinib is an orally bioavailable dual inhibitor of both the intracellular domain of the Her2 protein and the epidermal growth factor receptor. This dual inhibitor can effectively prevent the downstream signal transduction initiated by tyrosine kinase, thereby reducing the proliferation of tumor cells. Lapatinib was demonstrated to be beneficial in patients with Her2-positive locally advanced and metastatic breast cancer that had progressed after prior treatment with anthracycline, taxane, and trastuzumab. Because of their different mechanisms of drug actions, it may be useful to combine two drugs in order to provide improved clinically curative effects. Konecny et $\mathrm{al}^{4}$ found synergistic interactions between two agents in Her2-positive breast cancer models. If benefits such as decreasing the primary tumor and improving tumor response to chemotherapy ${ }^{5}$ could be achieved from neoadjuvant chemotherapy (NAC) alone, then using anti-Her2 agents together with NAC may provide a better outcome. It is therefore important to understand the efficacy and safety of a dual NAC/Her2-targeted therapy in the treatment of Her2-positive breast cancer patients. In this study, we evaluated pathologically complete response (pCR) rates when NAC was added to lapatinib, trastuzumab, or both in a meta-analysis of randomized clinical trials. We also evaluated the safety of these drugs and the influence of hormone-receptor (HR) status on treatment success.
The clinical response and the rate of breast conservation were also investigated as additional parameters.

\section{Methods}

\section{Search strategy}

We carried out searches of ClinicalTrials.gov and PubMed for randomized clinical trials. The keywords used included breast cancer, trastuzumab, lapatinib, and Her2. We also used some selected studies for inclusion in the analyses.

\section{Study criteria}

The randomized Phase II or III clinical trials divided patients into groups with interventions using NAC with trastuzumab, lapatinib, or both in accordance with the inclusion criteria. Further inclusion criteria were that the patients should have Her2-positive operable breast cancer, with a primary endpoint of pCR rates. We included the chemotherapy regimen in every study and ensured homogeneity between studies.

\section{Data extraction}

After the exclusion criteria were met, eight studies met all the criteria. We extracted the following data from each eligible study: author's name, trial phase, year of publication, number of patients enrolled, chemotherapy regimens used, treatment arms, HR status, and the endpoints.

\section{Assessment of risk of bias between included studies}

The random sequence generation, sample size, blinding procedure, loss to follow-up, dropout, and intentions to treat were used to assess the risk of bias between included studies. Jadad scoring was used to assess the quality of each study.

\section{Outcome definition}

The main objective of this analysis was to determine the pCR rate after adding trastuzumab, lapatinib, or both to NAC, to estimate the efficacy of different methods in anti-Her2 therapy. Two definitions of pCR were used in the included studies, no invasive tumors in breast only, or in breast and axillary nodes. We therefore adopted both as the endpoints. Other objectives, such as evaluating the safety of the drug, the influence of HR status, comparing the clinical responses, and the rates of breast conservation were also included.

\section{Statistical analyses}

We extracted the number of patients achieving pCR and the total number in each included trial, and then estimated the odds ratio (OR) between comparable groups and the 
$95 \%$ confidence interval (CI). In every trial, OR was calculated to evaluate the relative advantage of a group receiving NAC plus trastuzumab, lapatinib, or both. Assuming study variations existed, we used fixed effects or random effects model to complete the data analyses.

Cochran Q (significant cutoff point: $P=0.10$ ) and $I^{2}$ ( $I^{2}>50 \%$, strong heterogeneity) statistics were used to test the heterogeneity between studies.

All the analyses and graphs were obtained using RevMan 5.3 (The Nordic Cochrane Centre, The Cochrane Collaboration, Copenhagen, Denmark, https://tech.cochrane.org).

\section{Results}

\section{Study selection and exclusion}

The primary search yielded a total of 52 relevant studies: 42 randomized clinical trials from PubMed and ten studies from additional references. The strategies used for selecting eligible studies are shown in Figure 1. Among the eliminated studies, the RC0639 study took disease-free survival and overall survival as the endpoints, not the pCR rate. ${ }^{6}$

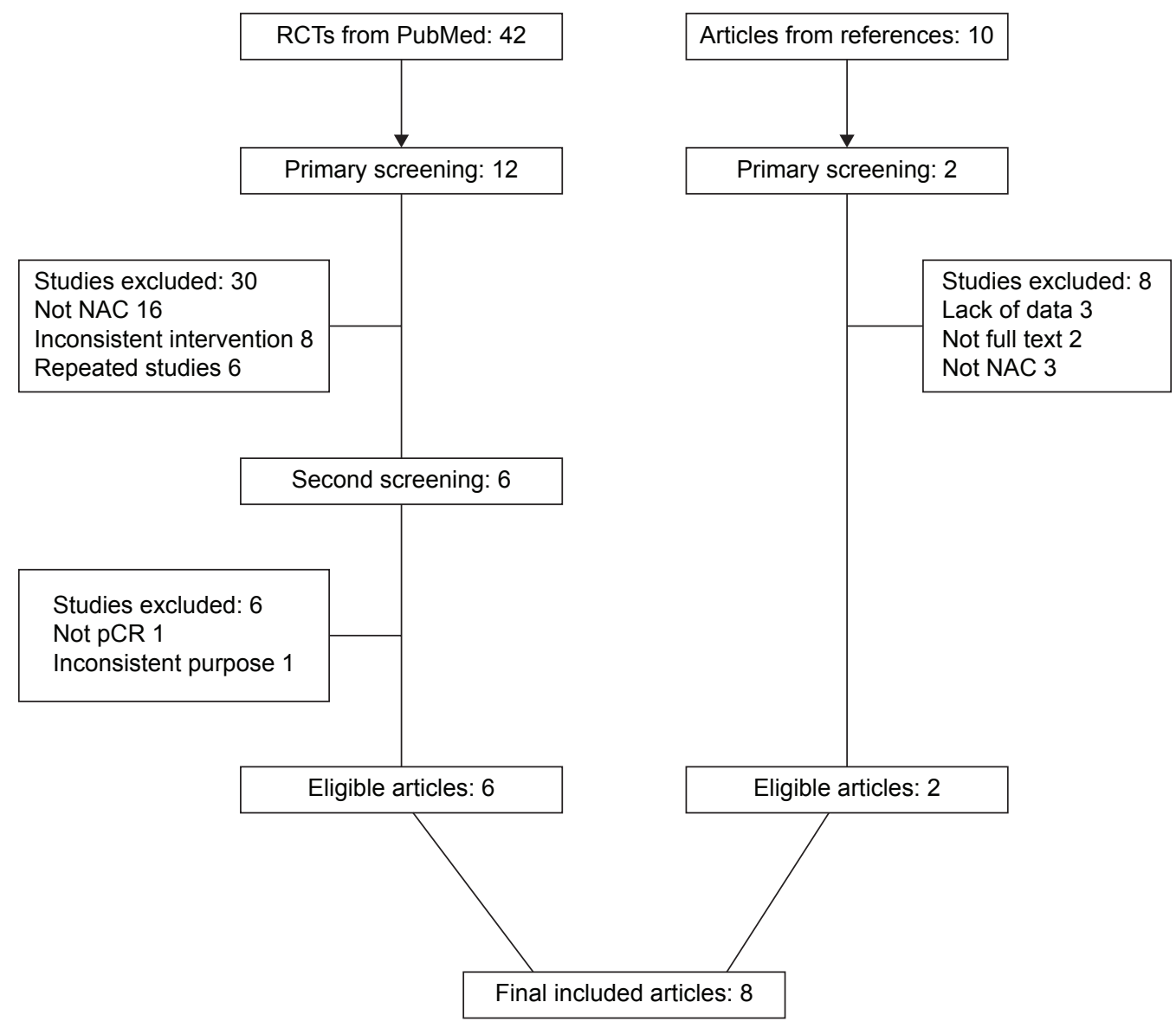

The clinical trial described by Davies et $\mathrm{al}^{7}$ had a purpose inconsistent with our study.

\section{Study characteristics}

Table 1 summarizes the baseline characteristics of the eight clinical trials that met the inclusion criteria and included 2,349 patients. The characteristics of the studies show that the eight studies were randomized control trials; the number of cases ranged from 100 to 700 cases. Six trials had three groups, which compared the addition of trastuzumab versus lapatinib versus their combination added to NAC; while the other two trials compared only trastuzumab versus lapatinib. Trastuzumab was used at a $4 \mathrm{mg} / \mathrm{kg}$ loading dose followed by $2 \mathrm{mg} / \mathrm{kg}$ in another six studies, while the other two studies used an $8 \mathrm{mg} / \mathrm{kg}$ loading dose followed by $6 \mathrm{mg} / \mathrm{kg}$. The dose of lapatinib ranged from 1,000 to $1,500 \mathrm{mg}$ given daily. Regarding the combination groups, lapatinib was administered at 1,000 mg. The Phase I safety, pharmacokinetics, and clinical activity study of lapatinib (GW572016) suggested that lapatinib was well tolerated at doses ranging

Figure I Flowchart of study search for the meta-analysis. Abbreviations: NAC, neoadjuvant chemotherapy; PCR, pathologically complete response; RCTs, randomized controlled trials. 


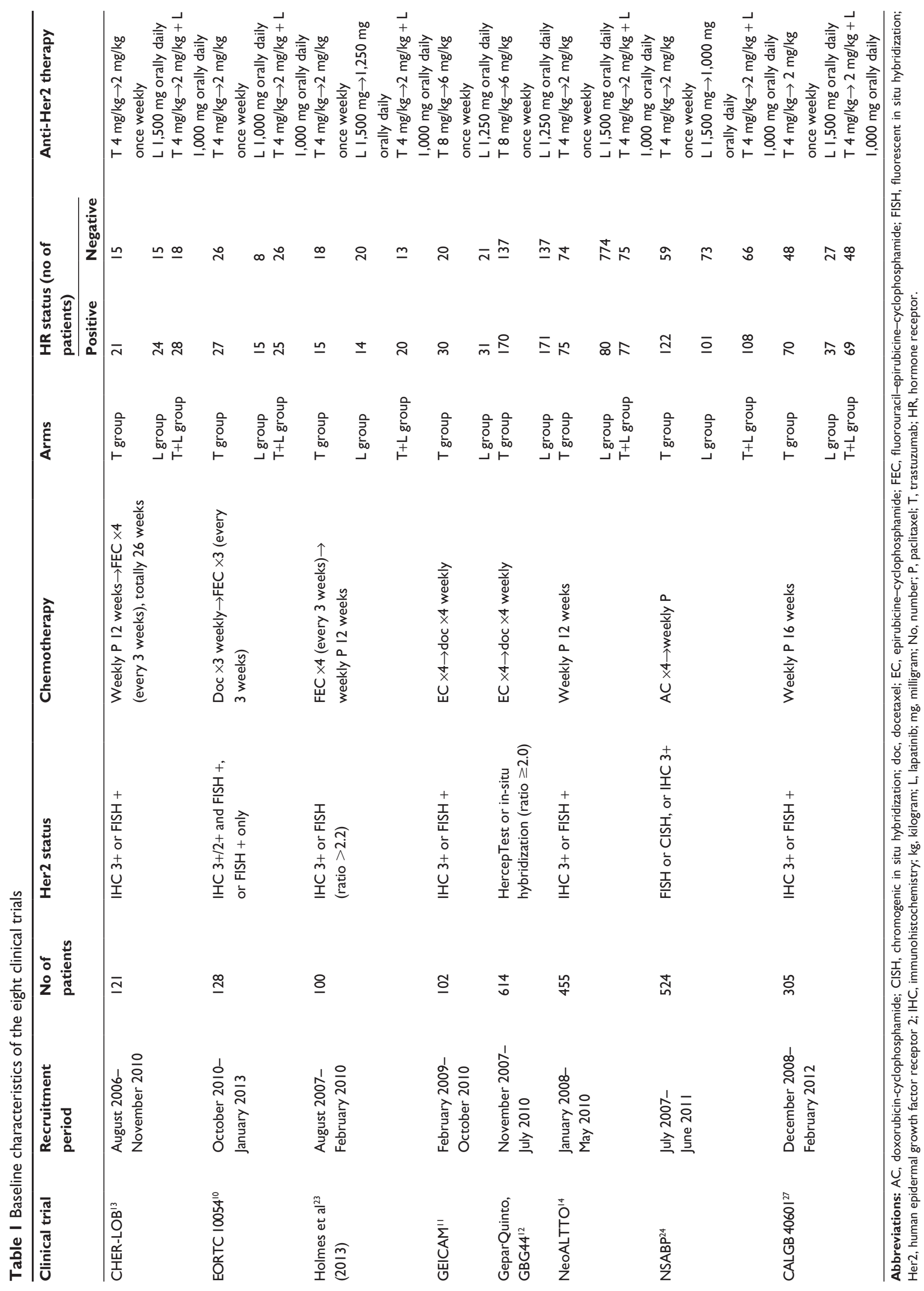


from 500 to $1,600 \mathrm{mg}$ given once daily, and clinical activity was observed most frequently at 900-1,200 mg. ${ }^{8}$ The clinical choice of dose was related to the tolerance to toxicities and there was no correlation between clinical response and different doses.

\section{Assessment of the methodological quality}

All trials had definitely established inclusion and exclusion criteria. All patients with Her2-positive breast cancer were randomized to receive different anti-Her2 therapy, including trastuzumab, lapatinib, or their combination. The anti-HER2 therapy was carried out simultaneously with NAC, and included fluorouracil-epirubicine-cyclophosphamide, epirubicine-cyclophosphamide, and doxorubicincyclophosphamide. HER2 amplification was confirmed by immunohistochemistry or fluorescent in situ hybridization, and HR status was recorded for every trial. Study quality was assessed using the five-item Jadad score (seven points), with a score range of 4-7 (Table 2).

\section{The $P C R$ rate of trastuzumab versus lapatinib}

Seven trials, including 1,694 patients $(n=887$ in the trastuzumab group and $n=807$ in the lapatinib group), were analyzed for the $\mathrm{pCR}$ rate after addition of trastuzumab versus lapatinib compared to NAC in breast only. The absolute pCR rate was estimated to be $41 \%$ in the trastuzumab group compared to $33 \%$ in the lapatinib group. The pCR rate tended to be higher in the trastuzumab group versus the lapatinib group (OR, 1.41, 95\% CI 1.14-1.73, $P=0.001$ ) (Figure 2A).

Eight trials including 1,752 patients $(n=915$ in trastuzumab group and $n=837$ in the lapatinib group) were compared for the pCR rates in breast and lymph nodes. The absolute pCR rate was estimated to be $38 \%$ in the trastuzumab group and 29\% in the lapatinib group. There were significant differences between the two groups, and the probability to achieve pCR was higher for the trastuzumab group versus the lapatinib group (OR, 1.50, 95\% CI 1.22-1.85, $P=0.0001)$ (Figure 2B).

\section{The $P C R$ rate of the combination treatment versus trastuzumab alone}

For this comparison, data were available from five trials, providing the endpoints of the rates of $\mathrm{pCR}$ in breast alone. Overall, 1,057 patients enrolled ( $\mathrm{n}=535$ in the combination group and $n=522$ in the trastuzumab group), and the $\mathrm{pCR}$ rate was significantly higher in the combination group than that in the trastuzumab group $(57.6 \%$ versus $44.6 \%$, OR, 1.70 , 95\% CI 1.33-2.19, $P<0.0001$ ) (Figure 3A).

The $\mathrm{pCR}$ rate in breast and lymph nodes could be obtained from five trials (1,017 patients; 510 patients treated with lapatinib plus trastuzumab and 507 patients treated with trastuzumab alone). It is noteworthy that the dual HER2targeted combination treatment achieved the higher rate of pCR in breast and lymph nodes (54\% versus $41 \%$, OR, 1.80 , 95\% CI 1.39-2.32, $P<0.00001$ ) (Figure 3B).

\section{Subgroup analysis: the influence of HR status}

Considering that the evaluation of biomarkers is highly recommended for the best management and therapeutic decision of breast cancer patient treatment, we divided patients into subgroups according to HR status in two comparisons, although the differences were small. The result showed that HR status contributed to the efficacy of different anti-Her2 therapies. In patients with HR-negative tumors, the pCR rate for the trastuzumab group, in breast only or in breast and lymph nodes, was significantly higher than for the lapatinib group. However, there was no significant difference in patients with HR-positive tumors (Figure 2). Similar outcomes were obtained with the comparison between the combination group and the trastuzumab group (Figure 3).

\section{The clinical response}

There were six trials providing comparison data of clinical response status between patients in the trastuzumab group and the lapatinib group. Four trials provided results comparing patients treated with trastuzumab plus lapatinib versus those treated using trastuzumab only. The percentage of patients

Table 2 The Jadad scale

\begin{tabular}{|c|c|c|c|c|c|c|c|c|}
\hline Clinical trials & CHER-LOB ${ }^{13}$ & $\begin{array}{l}\text { EORTC } \\
10054^{10}\end{array}$ & $\begin{array}{l}\text { Holmes } \\
\text { et } \mathrm{al}^{23}\end{array}$ & GEICAM ${ }^{\prime \prime}$ & $\begin{array}{l}\text { GeparQuinto, } \\
\text { GBG } 44^{12}\end{array}$ & NeoALTTO ${ }^{14}$ & NSABP24 & $\begin{array}{l}\text { CALGB } \\
4060 I^{27}\end{array}$ \\
\hline Randomization & 2 & 2 & 2 & $\mathrm{I}$ & 2 & 2 & 2 & 1 \\
\hline Concealment of allocation & 2 & 2 & 0 & 0 & 2 & 2 & 2 & 0 \\
\hline Double blinding & 2 & 2 & 2 & 2 & 2 & 2 & 2 & 2 \\
\hline Withdrawals and dropouts & 0 & I & I & $\mathrm{I}$ & I & I & $\mathrm{I}$ & I \\
\hline Jadad score ${ }^{a}$ & 6 & 7 & 5 & 4 & 7 & 7 & 7 & 4 \\
\hline
\end{tabular}

Notes: a Methodological quality of meditative movements studies reviewed using Jadad scoring criteria. Total score is 7. Scores I-3 considered as low quality; Scores $4-7$ considered as high quality. 


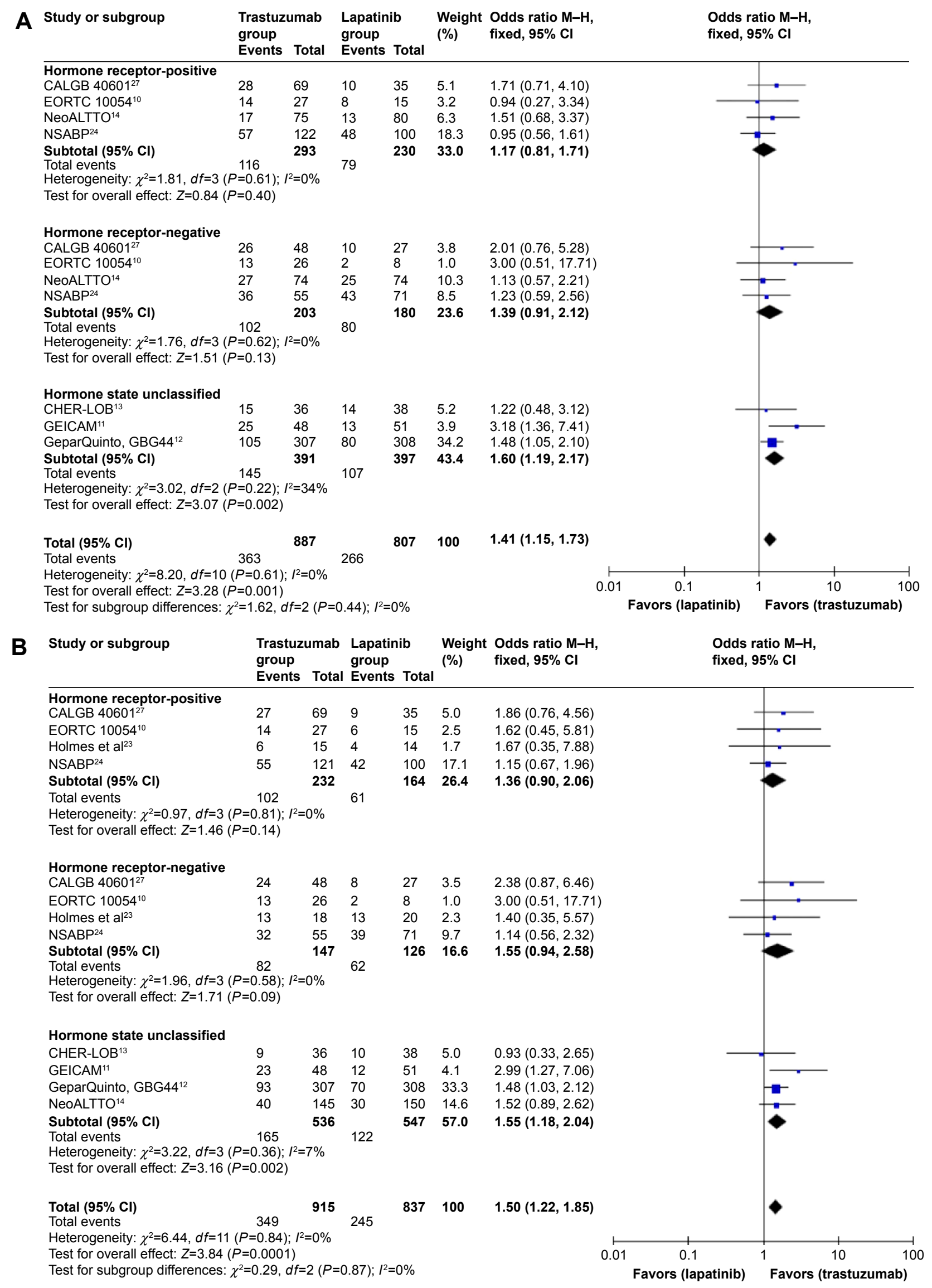

Figure 2 Forest plots of $P C R$ rates: trastuzumab versus lapatinib, defined as no invasive disease in the breast only (A) or no invasive disease in the breast and lymph nodes (B). Abbreviations: $\mathrm{Cl}$, confidence interval; $\mathrm{df}$, degrees of freedom; $\mathrm{M}-\mathrm{H}$, Mantel-Haenszel; pCR, pathologically complete response. 
A Study or subgroup

\section{Combination}

group

Events Total

Hormone receptor-positive

CALGB 4060127

EORTC $10054^{10}$

NeoALTTO ${ }^{14}$

NSABP $^{24}$

Subtotal $(95 \% \mathrm{Cl})$

Total events

Heterogeneity: $\chi^{2}=4.22, d f=3(P=0.24) ; l^{2}$

Test for overall effect: $Z=1.59(P=0.11)$

Hormone receptor-negative
CALGB $40601^{27}$
EORTC $10054^{10}$
NeoALTTO ${ }^{14}$
NSABP
Subtotal $(95 \% \mathrm{Cl})$

Total events

Heterogeneity: $\chi^{2}=2.52, d f=3(P=0.47) ; l^{2}=0 \%$

Test for overall effect: $Z=3.80(P=0.0001)$

$; I^{2}=29 \%$

\section{Trastuzumab Weight Odds ratio $\mathrm{M}-\mathrm{H}$, (\%) \\ Odds ratio $\mathrm{M}-\mathrm{H}$ \\ group \\ fixed, $95 \% \mathrm{Cl}$}

Events Total

$\begin{array}{ll}69 & 28 \\ 25 & 14 \\ 77 & 17 \\ 108 & 57 \\ 279 & \end{array}$

$\begin{array}{lll}69 & 17.5 & 1.00(0.51,1.97) \\ 27 & 7.4 & 0.86(0.29,2.55) \\ 75 & 10.6 & 2.43(1.20,4.91) \\ 112 & 26.1 & 1.21(0.71,2.05) \\ \mathbf{2 8 3} & \mathbf{6 1 . 6} & \mathbf{1 . 3 2}(\mathbf{0 . 9 4}, \mathbf{1 . 8 5})\end{array}$

$1.21(0.71,2.05)$

116

$\begin{array}{llllll}37 & 47 & 26 & 48 & 5.8 & 3.13(1.27,7.70) \\ 16 & 26 & 13 & 26 & 5.3 & 1.60(0.53,4.82) \\ 46 & 75 & 27 & 74 & 11.0 & 2.76(1.42,5.36) \\ 46 & 63 & 36 & 55 & 10.9 & 1.43(0.65,3.14) \\ & \mathbf{2 1 1} & & \mathbf{2 0 3} & \mathbf{3 3 . 0} & \mathbf{2 . 2 0}(\mathbf{1 . 4 6 , 3 . 3 0 )}\end{array}$

Hormone state unclassified

CHER-LOB ${ }^{13}$

Subtotal $(95 \% \mathrm{CI})$

Total events

Heterogeneity: Not applicable

Test for overall effect: $Z=2.42(P=0.02)$

$\begin{array}{llllll}31 & 45 & 15 & 36 & 5.5 & 3.10(1.24,7.74) \\ & 45 & & 36 & \mathbf{5 . 5} & \mathbf{3 . 1 0}(\mathbf{1 . 2 4}, \mathbf{7 . 7 4})\end{array}$

Total $(95 \% \mathrm{Cl})$

535

15

Heterogeneity: $\chi^{2}=12.12, d f=8(P=0.15) ; l^{2}=34 \%$

35

$522 \quad 100$

$1.70(1.33,2.19)$

Test for overall effect: $Z=4.20(P<0.0001)$

Test for subgroup differences: $\chi^{2}=5.40, d f=2(P=0.07) ; l^{2}=63.0 \%$ 
who achieved a clinically complete response was similar in patients treated with trastuzumab or lapatinib $(82.8 \%$ versus 82.4\%, OR, 0.99, 95\% CI 0.75-1.32, $P=0.95$ ) (Figure 4A). A similar result was observed for patients who were given dual Her2 block treatment or trastuzumab only ( $85.4 \%$ versus 82.2\%, OR, 1.34, 95\% CI 0.91-1.98, $P=0.14$ ) (Figure 4B).

\section{The rate of breast conservation}

Surgery was planned after the last chemotherapy administration and the candidates underwent breast conservation, or alternately, total mastectomy. The choice of surgery depended on the results obtained after chemical drug treatments. The rate of breast conservation between the groups showed no significant difference, either in the comparison groups of trastuzumab and lapatinib (50.5\% versus $47.5 \%$, OR, 1.812, 95\% CI 0.91-1.38, $P=0.27$ ) (Figure 5A) or in that of the combination group and trastuzumab-alone group (45.7\% versus $44.3 \%$, OR, 1.05 , 95\% CI $0.79-1.40, P=0.73$ ) (Figure 5B).

\section{Toxicity studies}

The main grade 3 and 4 toxic effects are summarized in Tables 3 and 4, and in Figure 6. After statistical analyses, the results showed that patients treated with lapatinib had more diarrhea, skin disorders, hepatic biochemical changes, infections, and inflammation $(P<0.05)$ (Table 3, Figure 6). For the combination group, diarrhea, other digestive tract symptoms, hepatic biochemical changes, and skin disorders occurred much more than in patients treated with trastuzumab alone (Tables 3 and 4, Figure 6).

\section{Discussion}

This study provides an analysis of the efficacy and safety of adding trastuzumab, lapatinib, or both to NAC in Her2-positive breast cancer patient treatments. Previous meta-analyses performed by Hicks et $\mathrm{al}^{9}$ showed an improvement in the pCR rate when lapatinib was combined with trastuzumab in patients receiving NAC. However, further analyses of the subgroups based on different HR status have not been performed. Furthermore, the toxic effects and breast conversation rates were not reported. In this study, we have updated the analysis by adding studies ${ }^{10-12}$ including the GEICAM/2006-14 trial, the GeparQuinto, GBG44 trial, and the EORTC 10054 study. In addition to including the pCR rates, we included the clinical responses, toxic effects, and the rates of breast conservation in the comparison analyses.

The overall pCR rate in the dual blockade of Her2 treatment groups was above 50\%, while the CALGB $40601^{13}$ and NeoALTTO ${ }^{14}$ studies reported $46.7 \%$ and $46.9 \%$, respectively. The different definitions of the $\mathrm{pCR}$ rate and statistical

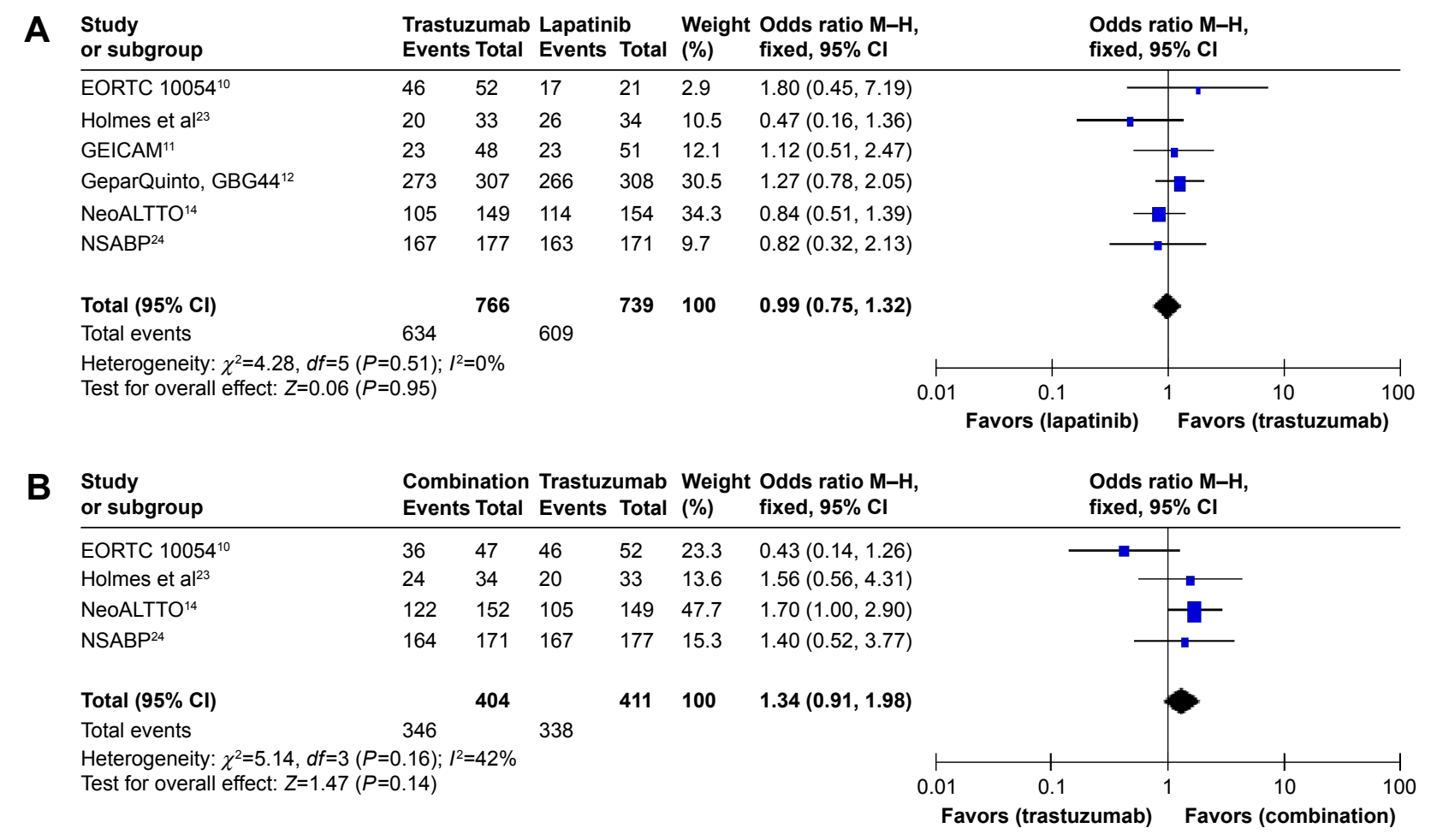

Figure 4 Forest plots of clinical complete response rates: trastuzumab versus lapatinib (A); combination versus trastuzumab (B). Abbreviations: $\mathrm{Cl}$, confidence interval; $d f$, degrees of freedom; $\mathrm{M}-\mathrm{H}$, Mantel-Haenszel. 


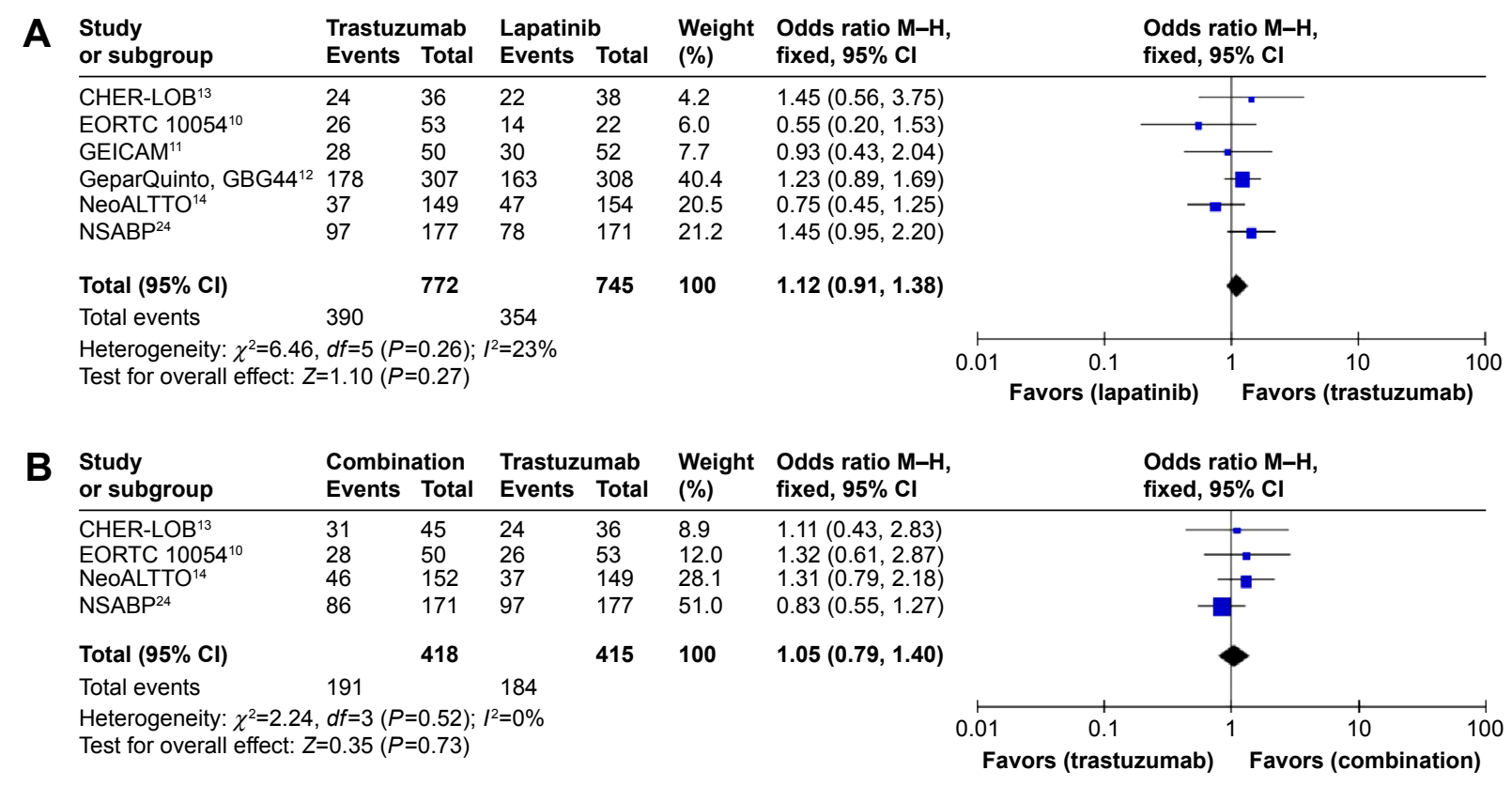

Figure 5 Forest plots of the rate of breast conservation: trastuzumab versus lapatinib (A); combination versus trastuzumab (B).

Abbreviations: $\mathrm{Cl}$, confidence interval; $d f$, degrees of freedom; $\mathrm{M}-\mathrm{H}$, Mantel-Haenszel.

bias might be the causes of the discrepancy in these results. In our analyses of the combination groups, the $\mathrm{pCR}$ rates, both in breast and in breast with lymph nodes, were $57.6 \%$ and $54 \%$ respectively, and were found to be superior to the single-agent treated groups. In addition, the pCR rate of the trastuzumab group was reported in articles that compared the effects of trastuzumab versus lapatinib. In our analyses,

Table 3 Selected toxic effects in the trastuzumab group and lapatinib group

\begin{tabular}{|c|c|c|c|}
\hline Toxic effect & Studies & Participants & $\begin{array}{l}\text { Odds ratio }(\mathrm{M}-\mathrm{H} \text {, } \\
\text { fixed, } 95 \% \mathrm{Cl})\end{array}$ \\
\hline Diarrhea & 8 & 1,769 & $0.11 *(0.07,0.18)$ \\
\hline $\begin{array}{l}\text { Other digestive } \\
\text { tract symptoms }\end{array}$ & 6 & $\mathrm{I}, 284$ & $0.92(0.59,1.44)$ \\
\hline Febrile neutropenia & 5 & 1,289 & $0.85(0.54,1.34)$ \\
\hline Neutropenia & 7 & 1,694 & $0.90(0.69,1.15)$ \\
\hline Hepatic & 8 & 1,769 & $0.60 *(0.39,0.92)$ \\
\hline Skin disorder & 7 & $\mathrm{I}, 703$ & $0.14 *(0.08,0.26)$ \\
\hline $\mathrm{CHF}$ & 3 & $|, 04|$ & $0.76(0.29,2.03)$ \\
\hline Hemoglobin & 4 & $\mathrm{I}, 107$ & $0.93(0.57,1.50)$ \\
\hline LVSD & 4 & $\mathrm{I}, \mathrm{I} 43$ & $\mathrm{I} .66(0.98,2.8 \mathrm{I})$ \\
\hline Fatigue & 5 & 1,218 & $0.83(0.55,1.26)$ \\
\hline Dehydration & 2 & 417 & $0.25(0.03,2.24)$ \\
\hline $\begin{array}{l}\text { Infection and } \\
\text { inflammation }\end{array}$ & 6 & 1,284 & $0.52 *(0.29,0.94)$ \\
\hline Neuropathy sensory & 5 & 1,298 & $0.69(0.36,1.3 \mathrm{I})$ \\
\hline Dyspnea & 3 & 492 & $\mathrm{I} .27(0.34,4.7 \mathrm{I})$ \\
\hline
\end{tabular}

Note: $* P<0.05$.

Abbreviations: CHF, congestive heart failure; $\mathrm{Cl}$, confidence interval; LVSD, left ventricular systolic dysfunction; M-H, Mantel-Haenszel. trastuzumab gave higher efficacy compared to lapatinib. The results suggest an advantage of adding trastuzumab to NAC as a more effective method, versus lapatinib alone, and showed elevated $\mathrm{pCR}$ rates either in breast or in breast and lymph nodes. These results could be explained by the lower ability of lapatinib to block the HER2 pathway, the lower drug dose of lapatinib used, and the greater ability

Table 4 Selected toxic effects in the combination group and trastuzumab group

\begin{tabular}{|c|c|c|c|}
\hline Toxic effect & Studies & Participants & $\begin{array}{l}\text { Odds ratio }(M-H \text {, } \\
\text { fixed, } 95 \% \mathrm{Cl})\end{array}$ \\
\hline Diarrhea & 6 & 1,135 & $14.38 *(8.02,25.78)$ \\
\hline $\begin{array}{l}\text { Other digestive } \\
\text { tract symptoms }\end{array}$ & 4 & 599 & $2.11 *(1.17,3.82)$ \\
\hline Febrile neutropenia & 4 & 517 & $0.92(0.46,1.85)$ \\
\hline Neutropenia & 5 & $\mathrm{I}, 053$ & $1.37(0.93,2.02)$ \\
\hline Hepatic & 6 & $\mathrm{I}, 135$ & $2.63 *(I .5 I, 4.59)$ \\
\hline Skin disorder & 5 & $\mathrm{I}, 072$ & $4.97 *(2.56,9.61)$ \\
\hline $\mathrm{CHF}$ & 2 & 454 & $0.14(0.02,1.17)$ \\
\hline Hemoglobin & 3 & 517 & $2.80(0.74,10.67)$ \\
\hline LVSD & 2 & 454 & $0.73(0.28,1.90)$ \\
\hline Fatigue & 3 & 536 & I.0I $(0.5 \mathrm{I}, 2.0 \mathrm{I})$ \\
\hline Dehydration & 3 & 517 & $3.15(0.32,30.76)$ \\
\hline $\begin{array}{l}\text { Infection and } \\
\text { inflammation }\end{array}$ & 4 & 599 & $2.26(0.82,6.29)$ \\
\hline Neuropathy sensory & 4 & 771 & $1.97(0.95,4.11)$ \\
\hline Dyspnea & 3 & 517 & $0.84(0.24,2.96)$ \\
\hline
\end{tabular}

Note: $* P<0.05$.

Abbreviations: CHF, congestive heart failure; $\mathrm{Cl}$, confidence interval; LVSD, left ventricular systolic dysfunction; M-H, Mantel-Haenszel. 


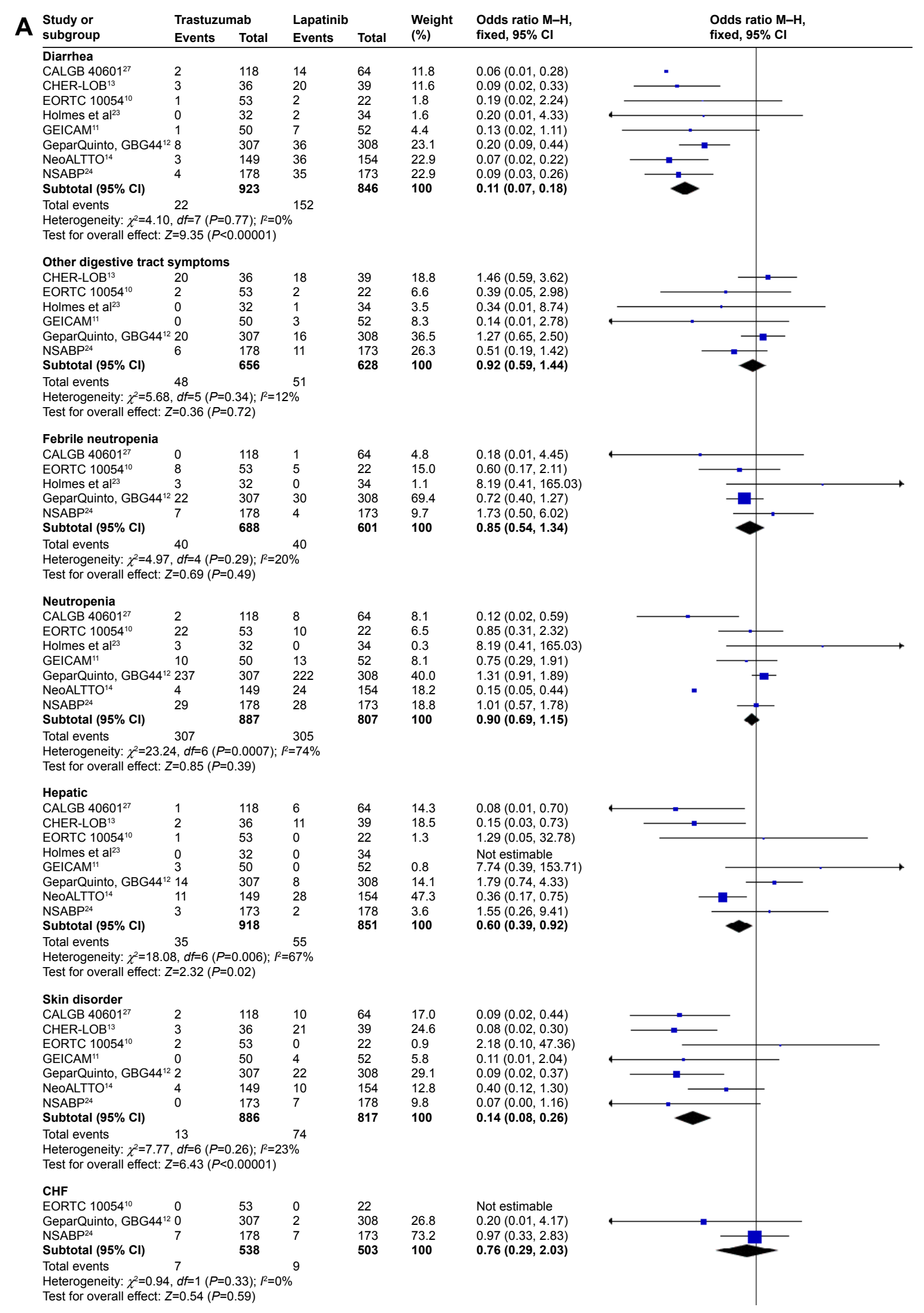

Figure 6 (Continued) 
Hemoglobin

EORTC 10054

GeparQuinto, GBG $44^{12} 6$

NSABP $^{24}$

Subtotal $(95 \% \mathrm{Cl})$

Total events

Heterogeneity: $\chi^{2}=1.04, d f=3(P=0.79) ; P=0 \%{ }^{37}$

Test for overall effect: $Z=0.31(P=0.76)$

LVSD

EORTC $10054^{10} \quad 0$

$\begin{array}{lr}\text { GEICAM }^{11} & 2 \\ {\text { GeparQuinto, GBG } 44^{12}}^{4}\end{array}$

NSABP $^{24}{ }^{24}$

Subtotal $(95 \% \mathrm{Cl})$

Total events

41

$\begin{array}{ll}53 & 1 \\ 50 & 1 \\ 307 & 1 \\ 178 & 22 \\ \mathbf{5 8 8} & \end{array}$

Heterogeneity: $\chi^{2}=2.99, d f=3(P=0.39) ; R=0 \%$

Test for overall effect: $Z=1.88(P=0.06)$

Fatigue

CHER-LOB ${ }^{13}$

EORTC $10054^{10}$

GEICAM $^{1}$

GeparQuinto, GBG44 ${ }^{12} 21$

NSABP $^{24}$

Subtotal $(95 \% \mathrm{Cl})$

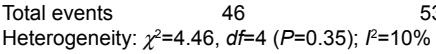

Test for overall effect: $Z=0.86(P=0.39)$

Dehydration

$\begin{array}{lll}\text { Holmes et al }{ }^{23} & 0 & 32\end{array}$

Subtotal $(95 \% \mathrm{CI})$

32
178

Subtotal $(95 \%$

Total events

210

Heterogeneity: $\chi^{2}=0.07, d f=1(P=0.80) ; R=0 \%$

Test for overall effect: $Z=1.24(P=0.21)$

Infection and inflammation

CHER-LOB ${ }^{13}$

EORTC $10054^{10}$

Holmes et al $^{23}$

Holmes et at

GEICAM $^{11} \quad 0$

GeparQuinto, GBG4412 12

NSABP $^{24}$

Subtotal $(95 \% \mathrm{Cl})$

Total events

Heterogeneity: $\chi^{2}=1.29, d f=5(P=0.94) ; R=0 \%$

Test for overall effect: $Z=2.17(P=0.03)$

Neuropathy sensory

EORTC $10054^{10}$

GeparQuinto, GBG44 $4^{12} 6$

NSABP24

Subtotal $(95 \% \mathrm{Cl})$

Total events

$\begin{array}{ll}36 & 4 \\ 53 & 2 \\ 32 & 2\end{array}$

32

$50 \quad 2$

$307 \quad 18$

178
656

4

Heterogeneity: $\chi^{2}=0.91, d f=4(P=0.92) ; R=0 \%$

Test for overall effect: $Z=1.13(P=0.26)$

Dyspnoea

EORTC $10054^{10}$

Holmes et a

Subtotal $(95 \% \mathrm{Cl})$

Total events

Heterogeneity: $\chi^{2}=2.47, d f=1 \quad(P=0.12) ; P=60 \%$

Test for overall effect: $Z=0.36(P=0.72)$

Test for subgroup differences: $\chi^{2}=109.29, d f=13(P<0.00001) ; R^{2}=88.1 \%$

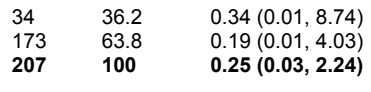

$\begin{array}{lll}39 & 11.3 & 0.51(0.09,3.00) \\ 22 & 8.5 & 0.39(0.05,2.98) \\ 34 & 5.9 & 0.52(0.04,5.99) \\ 52 & 7.6 & 0.20(0.01,4.27) \\ 308 & 54.0 & 0.66(0.31,1.38) \\ 173 & 12.6 & 0.24(0.03,2.16) \\ \mathbf{6 2 8} & \mathbf{1 0 0} & \mathbf{0 . 5 2}(\mathbf{0 . 2 9}, \mathbf{0 . 9 4})\end{array}$

$1.33(0.40,4.40)$ $0.39(0.05,2.98)$ $3.41(0.65,17.77)$ $0.68(0.38,1.22)$ $0.73(0.31,1.72)$

$0.83(0.55,1.26)$

$\begin{array}{lll}173 & 25.2 & 0.73(0.31,1.72) \\ \mathbf{5 9 4} & \mathbf{1 0 0} & \mathbf{0 . 8 3}(\mathbf{0 . 5 5}, \mathbf{1 . 2 6})\end{array}$

$B$

Study or
subgroup

Diarrhea

CALGB 4060127

CHER-LOB ${ }^{13}$

EORTC $10054^{10}$

Holmes et a ${ }^{23}$

NeoALTTO ${ }^{14}$

NSABP $^{24}$

Subtotal $(95 \% \mathrm{Cl})$

$\begin{array}{lcc}\text { Total events } \quad 142 & 13 \\ \text { Heterogeneity: } \chi^{2}=0.56, d f=5 & (P=0.99) ; P^{2}=0 \%\end{array}$

Test for overall effect: $Z=8.95(P<0.00001)$

Figure 6 (Continued)
$1.29(0.05,32.78)$

$0.97(0.55,1.71)$

$0.13(0.01,3.42)$

$4.05(0.45,36.47)$

$\mathbf{1 . 6 6}(\mathbf{0 . 9 8}, \mathbf{2 . 8 1})$ $2.13(0.19,24.20)$

$71(0.15,3.29)$ $0.21(0.01,4.43)$ $1.29(0.05,32.78)$ $0.86(0.28,2.58)$

$0.64(0.22,1.83)$

$\begin{array}{lll}173 & 39.2 & 0.64(0.22,1.83) \\ \mathbf{6 0 6} & \mathbf{1 0 0} & \mathbf{0 . 6 9}(\mathbf{0 . 3 6}, \mathbf{1 . 3 1})\end{array}$
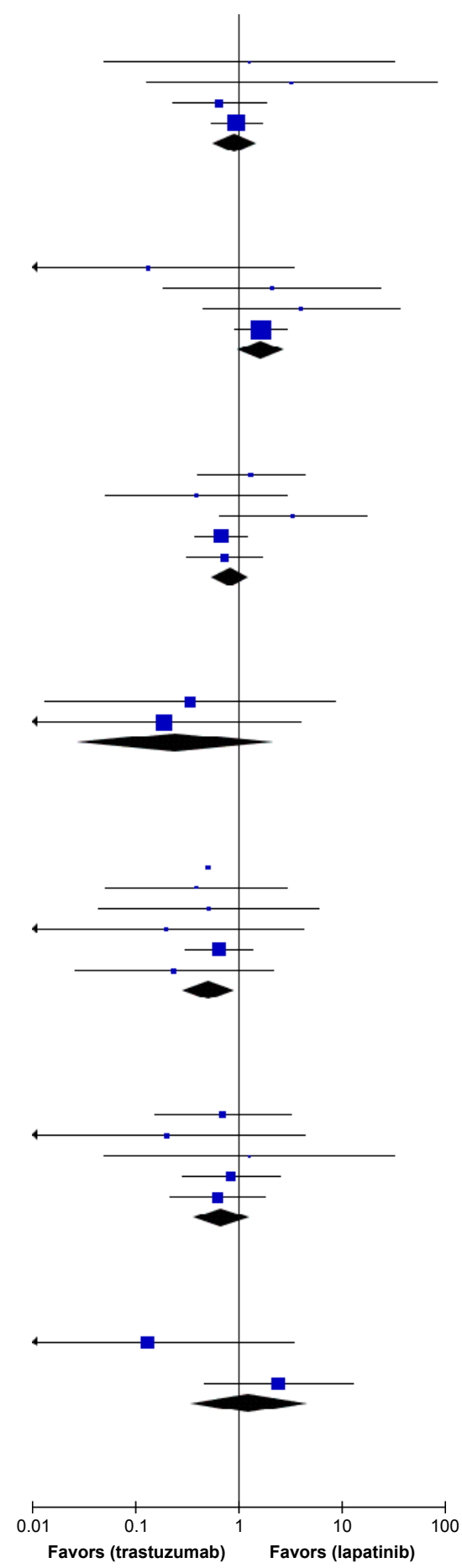

Favors (trastuzumab) Favors (lapatinib)

Odds ratio $\mathrm{M}-\mathrm{H}$,

fixed, $95 \% \mathrm{Cl}$

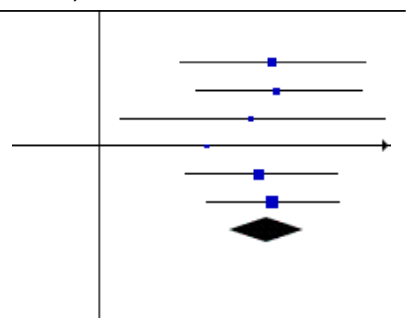


Other digestive tract symotoms

$\begin{array}{llll}\text { CHER-LOB }^{13} & 32 & 46 & 20\end{array}$

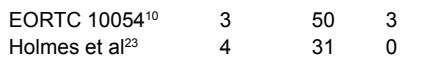

NSABP $^{24}$

Subtotal $(95 \% \mathrm{Cl})$

13

$\begin{array}{lcc}\text { Total events } & 52 & 29 \\ \text { Heterogeneity: } \chi^{2}=1.94, d f=3 & (P=0.59) ; P^{2}=0 \%\end{array}$

Test for overall effect: $Z=2.47(P=0.01)$

Febrile neutropenia

EORTC $10054^{10} \quad 5$

NSABP 24

Subtotal $(95 \% \mathrm{Cl})$

Total events $\quad 16 \quad 18$

$\begin{array}{ll}31 & 3 \\ 173 & 7\end{array}$

173
254

Test for overall effect: $Z=0.23(P=0.81)$

Neutropenia

CALGB 406

EORTC $10054^{10}$

Holmes et $\mathrm{al}^{23}$

NeoALTTO ${ }^{14}$

NSABP $^{24}$

Subtotal $(95 \% \mathrm{Cl})$

$\begin{array}{lcc}\text { Total events } & 74 & 60 \\ \text { Heterogeneity: } & \chi^{2}=6.96, d f=4 & (P=0.14) ;{ }^{2}=43 \%\end{array}$

Test for overall effect: $Z=1.58(P=0.11)$

Hepatic

CALGB $40601^{27}$

CHER-LOB ${ }^{13}$

EORTC $10054^{10}$

Holmes et $\mathrm{al}^{23}$

NeoALTTO ${ }^{14}$

NSABP $^{24}$

Subtotal $(95 \% \mathrm{Cl})$

$\begin{array}{lcc}\text { Total events } & 47 & 18 \\ \text { Heterogeneity: } \chi^{2}=5.80, d f=5(P=0.33) ; P^{P}=14 \%\end{array}$

Test for overall effect: $Z=3.41(P=0.0006)$

Skin disorder

CALGB $40601^{27}$

CALGB 406

EORTC $10054^{10}$

NeoALTTO ${ }^{14}$

NSABP $^{24}$

Subtotal $(95 \% \mathrm{CI})$

Total events

Heterogeneity: $\chi^{2}=4.15, d f=4(P=0.39) ; P^{2}=4 \%$

Test for overall effect: $Z=4.75(P<0.00001)$

CHF

EORTC $10054^{10} \quad 0 \quad 50 \quad 0$

Total events

$\begin{array}{llll}173 & 7 & 178 & 100 \\ \mathbf{2 2 3} & & \mathbf{2 3 1} & \mathbf{1 0 0}\end{array}$

Not estimable

$0.14(0.02,1.17)$

Heterogeneity: Not applicable

Test for overall effect: $Z=1.82(P=0.07)$

Hemoglobin

EORTC $10054^{10}$

Holmes et $\mathrm{al}^{23}$

NSABP $^{24}$

Subtotal $(95 \% \mathrm{CI})$

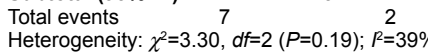

Test for overall effect: $Z=1.51(P=0.13)$

LVSD

$\begin{array}{lllllll}\text { EORTC } 10054^{10} & 3 & 50 & 0 & 53 & 4.5 & 7.88(0.40,156.60) \\ \text { NSABP }^{24} & 4 & 173 & 10 & 178 & 95.5 & 0.40(0.12,1.29)\end{array}$

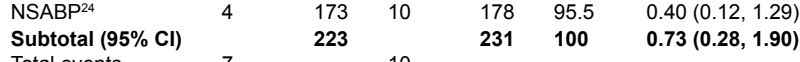

$\begin{array}{lcc}\text { Total events } & 7 & 10 \\ \text { Heterogeneity: } & \chi^{2}=3.46, d f=1 & (P=0.06)\end{array} P^{2}=71 \%$

Test for overall effect: $Z=0.64(P=0.52)$

Figure 6 (Continued)

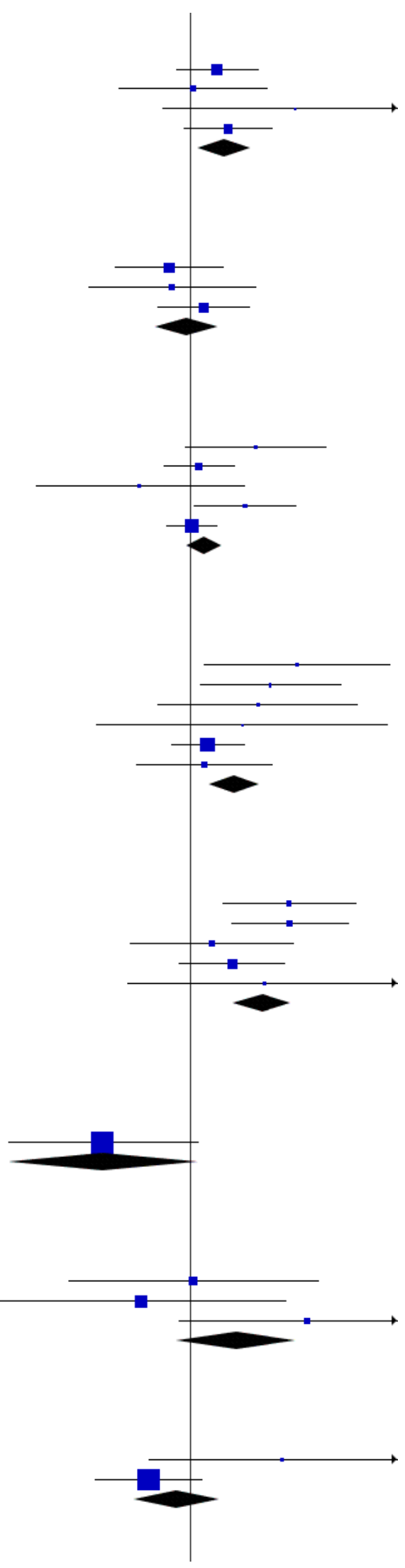

$0.14(0.02,1.17)$

$6.00(1.25,28.86)$

$4.52(0.49,41.92)$

$3.20(0.13,81.50)$

$.48(0.66,3.30)$

$2.63(1.51,4.59)$

$9.19(2.06,40.93)$

$9.24(2.48,34.47)$

$.63(0.26,10.17)$

$5.20(0.25,109.18)$

$4.97(2.56,9.61)$

$1.06(0.06,17.44)$

$0.33(0.01,8.50)$

$13.85(0.77,247.82)$

$2.80(0.74,10.67)$ 


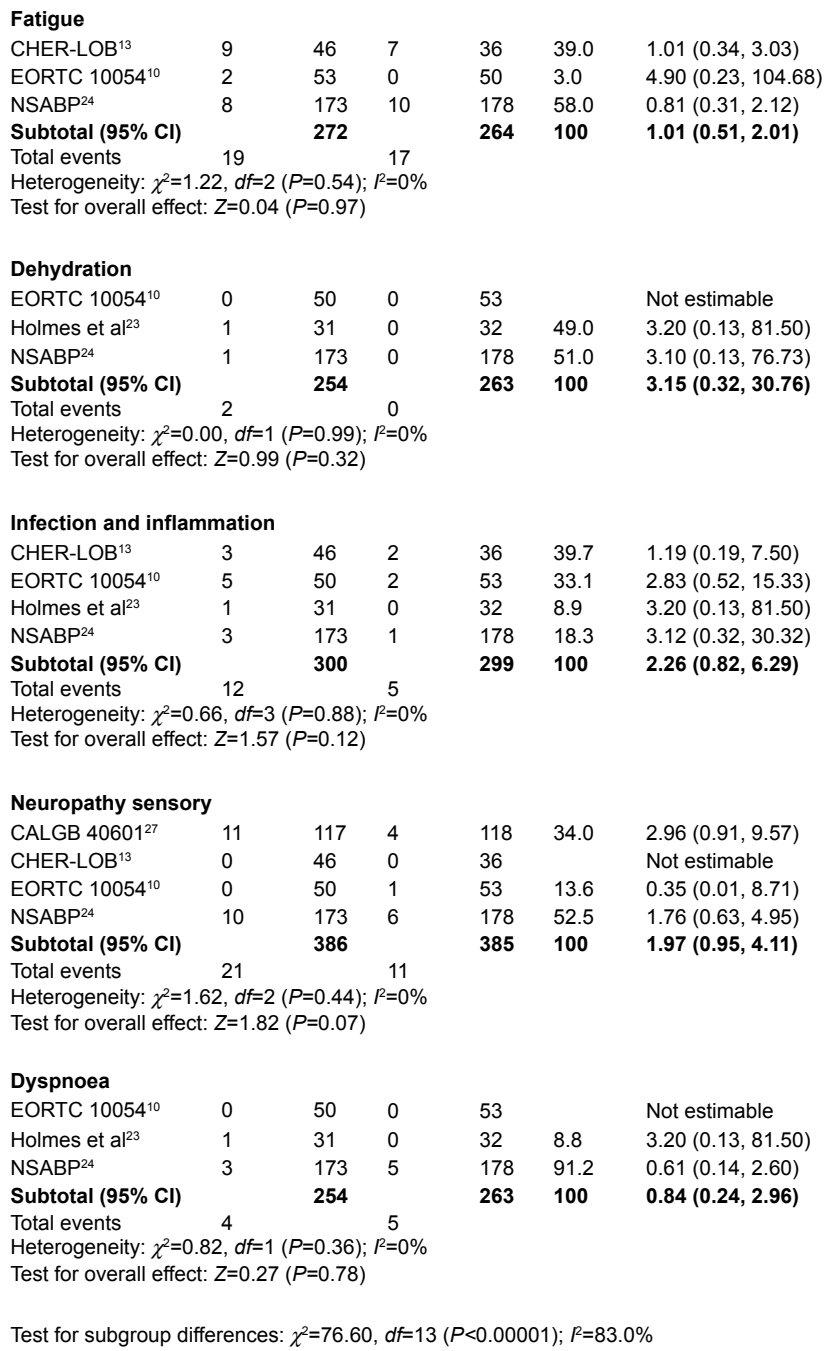

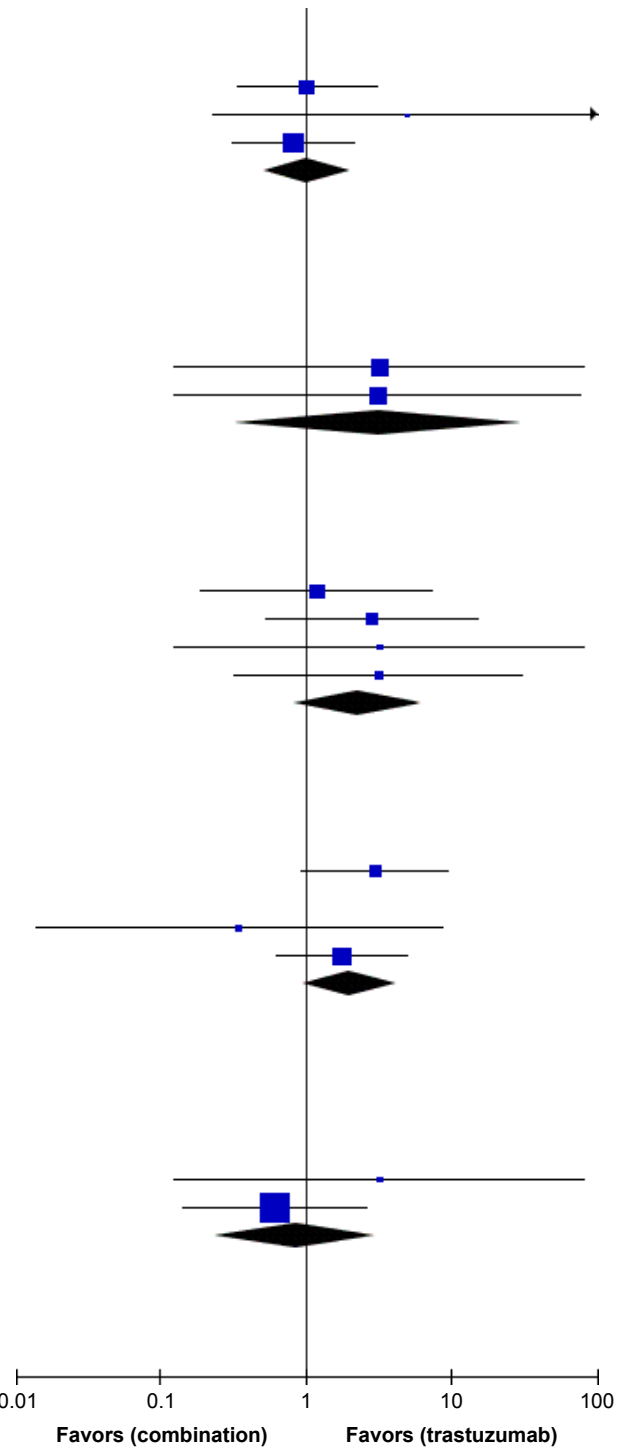

Figure 6 Forest plots of the toxic effect, trastuzumab versus lapatinib (A); combination versus trastuzumab (B).

Abbreviations: $\mathrm{CHF}$, congestive heart failure; $\mathrm{Cl}$, confidence interval; $d f$, degrees of freedom; LVSD, left ventricular systolic dysfunction; $\mathrm{M}-\mathrm{H}$, Mantel-Haenszel.

of trastuzumab to recruit immune cells that are responsible for antibody-dependent cytotoxicity ${ }^{15}$ and inhibition of angiogenesis. ${ }^{16}$

The use of the dual blockade of Her2 is supported by biological and clinical data. Trastuzumab and lapatinib are well-known drugs that inhibit the function of Her2 by different mechanisms. ${ }^{17}$ The expression product of the Her 2 gene is an oncogenic membrane-spanning protein that is processed externally at membrane sites. Because of its specific overexpression in tumor cells, it can be used as a target antigen for breast cancer therapy. Trastuzumab, a monoclonal antibody to Her2, combines with the extracellular domain of Her $2,{ }^{18}$ thereby inducing the growth arrest of cells in G1 and the decrease of cell amplification. Regarding lapatinib, it can inhibit the tyrosine-kinase activity of both the epidermal growth factor receptor and ErbB-2 (Her2). This dual inhibitory activity can effectively prevent downstream signal transduction, thus preventing the proliferation of tumor cells. Taking the different mechanisms of drug action of trastuzumab and lapatinib into consideration, we suggest that the combination of these two drugs can provide a more optimal clinical curative effect.

Whether pCR can be used as a surrogate for disease-free survival rates in HER2-positive breast carcinomas, particularly those that are HR-positive, remains to be determined. Studies have confirmed that the higher the pCR rates, 
the better the disease-free survival and overall survival can be achieved; but this effect may be limited to HR-negative tumors. ${ }^{19}$ However, within the same group of Her2-positive patients, when accepting the same method of anti-Her2 therapy, the outcome ( $\mathrm{pCR}$ ) could vary. The differences in results obtained in the included studies were not due to statistical errors. Untch et $\mathrm{al}^{12}$ reported that the absence of HR expression was an important predictor of $\mathrm{pCR}$. Therefore, we hypothesize that a relationship between HR state and the drug effects exists. Interestingly, when we set the subgroups according to HR status, a significant difference for the pCR was found only in the HR-negative subgroups. This indicated that some relationships existed between HR and Her2, or that resistance to anti-Her2 agents existed. A previous study ${ }^{20}$ showed impaired survival in patients with estrogen receptor-negative tumors. Estrogen receptor negativity has been reported to have a negative prognostic impact in breast cancer patients with Her2-positive tumors. $^{21,22}$ Further exploration of interactions between HR and Her2 will help to evaluate prognosis and to guide future treatment strategies.

Regarding toxicity of the drugs, some grade 3 and 4 toxic effects, such as diarrhea and skin disorder were more common in the lapatinib and dual-drug treated groups. This suggests both advantages and disadvantages to the patients, with some severe toxic effects from treatments.

Some trials reported additional operative procedures $^{10-12,14,23,24}$ for patients after NAC with anti-Her2 therapy. Although dual Her2 inhibition provides better $\mathrm{pCR}$ rates, this provides no significant improvement in the rate of breast conservation. Breast conservative therapy (BCT) is reported to provide long-term survival rates equivalent to those of total mastectomy. ${ }^{22}$ Tan et $\mathrm{al}^{25}$ performed a retrospective analysis in patients with breast malignancies and found that BCT was achieved in $85 \%$ of the patients with multifocal and multicentric breast cancer without evidence of poorer local control. Benediktsson and Perbeck ${ }^{26}$ reported a series of 216 patients who underwent conservative mastectomy with a long follow-up (median 13 years). The 10 -year frequency of local recurrence rate was $8.5 \%$ when patients accepted radio therapy according to international guidelines. Because BCT provides better cosmetic results and improves the quality of life, it is necessary to identify the indications for BCT. In our analyses, there was no relationship between anti-Her2 therapy and BCT. However, considering the limited studies included here, further investigations are needed.

\section{Conclusion}

In our study, we found that the combination of trastuzumab and lapatinib was superior to single-agent treatment for improved pCR rate. However, combination treatment was not effective in improving the rate of breast conservation. Furthermore, a higher risk for toxicity was associated with combined administration. There are limitations to this study. First, only English language literature was included. Second, although we chose only the randomized clinical trials, there was relative heterogeneity in the study, especially when it came to analyzing the toxicity effects. Finally, the chemotherapy regimens used in the included articles were not the same, and this could be a cause of the differences in reported pCR rates among the included groups. Based on clinical requirements, a larger study, including more evidence to verify the conclusions proposed here, is required.

\section{Disclosure}

The authors report no conflicts of interest in this work.

\section{References}

1. Ross JS, Slodkowska EA, Symmans WF, Pusztai L, Ravdin PM, Hortobagyi GN. The HER-2 receptor and breast cancer: ten years of targeted anti-HER-2 therapy and personalized medicine. Oncologist. 2009; 14:320-368.

2. Olson EM. Maximizing human epidermal growth factor receptor 2 inhibition: a new oncologic paradigm in the era of targeted therapy. J Clin Oncol. 2012;30:1712-1714.

3. Pegram MD, Finn RS, Arzoo K, Beryt M, Pietras RJ, Slamon DJ. The effect of HER-2/neu overexpression on chemotherapeutic drug sensitivity in human breast and ovarian cancer cells. Oncogene. 1997;15: 537-547.

4. Konecny GE, Venkatesan N, Yang G, et al. Activity of lapatinib a novel HER2 and EGFR dual kinase inhibitor in human endometrial cancer cells. Br J Cancer. 2008;98:1076-1084.

5. Fisher B, Bryant J, Wolmark N, et al. Effect of preoperative chemotherapy on the outcome of women with operable breast cancer. J Clin Oncol. 1998;16:2672-2685.

6. Moreno-Aspitia A, Dueck AC, Ghanem-Canete I, et al. RC0639: phase II study of paclitaxel, trastuzumab, and lapatinib as adjuvant therapy for early stage HER2-positive breast cancer. Breast Cancer Res Treat. 2013;138:427-435.

7. Davies BR, Greenwood H, Dudley P, et al. Preclinical pharmacology of AZD5363, an inhibitor of AKT: pharmacodynamics, antitumor activity, and correlation of monotherapy activity with genetic background. Mol Cancer Ther. 2012;11:873-887.

8. Burris HR, Hurwitz HI, Dees EC, et al. Phase I safety, pharmacokinetics, and clinical activity study of lapatinib (GW572016), a reversible dual inhibitor of epidermal growth factor receptor tyrosine kinases, in heavily pretreated patients with metastatic carcinomas. J Clin Oncol. 2005;23:5305-5313.

9. Hicks M, Macrae ER, Abdel-Rasoul M, et al. Neoadjuvant dual HER2targeted therapy with lapatinib and trastuzumab improves pathologic complete response in patients with early stage HER2-positive breast cancer: a meta-analysis of randomized prospective clinical trials. Oncologist. 2015;20:337-343. 
10. Bonnefoi H, Jacot W, Saghatchian M, et al. Neoadjuvant treatment with docetaxel plus lapatinib, trastuzumab, or both followed by an anthracycline-based chemotherapy in HER2-positive breast cancer: results of the randomised phase II EORTC 10054 study. Ann Oncol. 2015;26:325-332.

11. Alba E, Albanell J, de la Haba J, et al. Trastuzumab or lapatinib with standard chemotherapy for HER2-positive breast cancer: results from the GEICAM/2006-14 trial. Br J Cancer. 2014;110:1139-1147.

12. Untch M, Loibl S, Bischoff J, et al. Lapatinib versus trastuzumab in combination with neoadjuvant anthracycline-taxane-based chemotherapy (GeparQuinto, GBG 44): a randomised phase 3 trial. Lancet Oncol. 2012;13:135-144.

13. Guarneri V, Frassoldati A, Bottini A, et al. Preoperative chemotherapy plus trastuzumab, lapatinib, or both in human epidermal growth factor receptor 2-positive operable breast cancer: results of the randomized phase II CHER-LOB study. J Clin Oncol. 2012;30:1989-1995.

14. Baselga J, Bradbury I, Eidtmann H, et al. Lapatinib with trastuzumab for HER2-positive early breast cancer (NeoALTTO): a randomised, open-label, multicentre, phase 3 trial. Lancet. 2012;379:633-640.

15. Weiner LM, Adams GP. New approaches to antibody therapy. Oncogene. 2000;19:6144-6151.

16. Viloria-Petit A, Crombet T, Jothy S, et al. Acquired resistance to the antitumor effect of epidermal growth factor receptor-blocking antibodies in vivo: a role for altered tumor angiogenesis. Cancer Res. 2001;61: 5090-5101.

17. Konecny GE, Pegram MD, Venkatesan N, et al. Activity of the dual kinase inhibitor lapatinib (GW572016) against HER-2-overexpressing and trastuzumab-treated breast cancer cells. Cancer Res. 2006;66: 1630-1639.

18. Ahmed S, Sami A, Xiang J. HER2-directed therapy: current treatment options for HER2-positive breast cancer. Breast Cancer. 2015; 22:101-116

19. Hamy-Petit AS, Belin L, Bonsang-Kitzis H, et al. Pathological complete response and prognosis after neoadjuvant chemotherapy for HER2positive breast cancers before and after trastuzumab era: results from a real-life cohort. Br J Cancer. 2016;114:44-52.
20. Duchnowska R, Wysocki PJ, Korski K, et al. Immunohistochemical prediction of lapatinib efficacy in advanced HER2-positive breast cancer patients. Oncotarget. 2016;7(1):550-564.

21. Kennecke H, Yerushalmi R, Woods R, et al. Metastatic behavior of breast cancer subtypes. J Clin Oncol. 2010;28:3271-3277.

22. Clarke M, Collins R, Darby S, et al. Effects of radiotherapy and of differences in the extent of surgery for early breast cancer on local recurrence and 15-year survival: an overview of the randomised trials. Lancet. 2005;366:2087-2106.

23. Holmes FA, Espina V, Liotta LA, et al. Pathologic complete response after preoperative anti-HER2 therapy correlates with alterations in PTEN, FOXO, phosphorylated Stat5, and autophagy protein signaling. BMC Res Notes. 2013;6:507.

24. Robidoux A, Tang G, Rastogi P, et al. Lapatinib as a component of neoadjuvant therapy for HER2-positive operable breast cancer (NSABP protocol B-41): an open-label, randomised phase 3 trial. Lancet Oncol. 2013;14:1183-1192.

25. Tan MP, Sitoh NY, Sitoh YY. Optimising breast conservation treatment for multifocal and multicentric breast cancer: a worthwhile endeavour? World J Surg. 2016;40:315-322.

26. Benediktsson KP, Perbeck L. Survival in breast cancer after nipplesparing subcutaneous mastectomy and immediate reconstruction with implants: a prospective trial with 13 years median follow-up in 216 patients. Eur J Surg Oncol. 2008;34:143-148.

27. Carey LA, Berry DA, Cirrincione CT, et al. Molecular heterogeneity and response to neoadjuvant human epidermal growth factor receptor 2 targeting in CALGB 40601, a randomized phase III trial of paclitaxel plus trastuzumab with or without lapatinib. J Clin Oncol. 2016;34(6):542-549.
OncoTargets and Therapy

\section{Publish your work in this journal}

OncoTargets and Therapy is an international, peer-reviewed, open access journal focusing on the pathological basis of all cancers, potential targets for therapy and treatment protocols employed to improve the management of cancer patients. The journal also focuses on the impact of management programs and new therapeutic agents and protocols on

\section{Dovepress}

patient perspectives such as quality of life, adherence and satisfaction. The manuscript management system is completely online and includes a very quick and fair peer-review system, which is all easy to use. Visit http://www.dovepress.com/testimonials.php to read real quotes from published authors. 